\title{
Endovascular management of a late saccular aortic aneurysm after end-to-end repair of coarctation
}

\section{Trattamento endovascolare di un aneurisma aortico sacculare tardivo dopo riparazione termino-terminale di coartazione aortica}

\author{
Christophoros Kotoulas ${ }^{1}$, Vasileios Tzilalis ${ }^{1}$, \\ Emmanouil Spyridakis¹, Ioannis Mamarelis2
}

\begin{abstract}
Endovascular management of a late saccular aortic aneurysm after end-to-end repair of coarctation. C. Kotoulas, V. Tzilalis, E. Spyridakis, I. Mamarelis.

Post-coarctation surgical repair aneurysm formation is observed rarely with end-to-end anastomosis technique. The redo surgery is associated with high mortality and morbidity rate. Although the minimal invasive method with stented grafts has been reported in only small number
\end{abstract}

of patients, this could represent a valid alternative treatment. We present a case of successful endovascular treatment of a patient with a late post-coarctation repair saccular aneurysm.

Keywords: aortic coarctation, postoperative, stent-graft, complication, aortic aneurysm, minimal invasive surgery

Monaldi Arch Chest Dis 2011; 76: 208-210.

1 Dept of Cardiothoracic Surgery, «IASO» General Hospital of Athens.

2 Dept of Cardiology, NIMTS General Hospital of Athens.

Corresponding author: Christophoros Kotoulas MD, PhD, FETCS, FCCP; Kifissias Ave 38, Ampelokipoi; Athens, GR-11526 Greece; Tel.0030210 7782220; Fax 0030210 7772329; E-mail address: info@kotoulas.com; Website: www.kotoulas.com

\section{Introduction}

Severe adult-type coarctation accounts for $4 \%$ of congenital cardiovascular malformation and is usually corrected by surgical repair. Despite primary success, long-term studies demonstrated late problems principally caused by recoarctation, hypertension, and premature coronary and cerebrovascular disease [1].

Herein, we present the case of successful endovascular treatment of a patient with a late post-coarctation saccular aneurysm after end-to-end anastomosis repair and co-existing ischemic heart disease.

Case report

A 78-year-old Caucasian male, obese, hypertensive, former smoker, asymptomatic albeit with known coronary artery disease, which has been subjected to PTCA in the past, underwent a CT scan that revealed the existence of a saccular aneurysm beginning from the end of the aortic arch with $54 \mathrm{~mm}$ length and maximum anteroposterior and transverse diameters of 46 and $51 \mathrm{~mm}$, respectively (Figure 1). The dimensions of the ascending and the descending aorta were normal. The patient

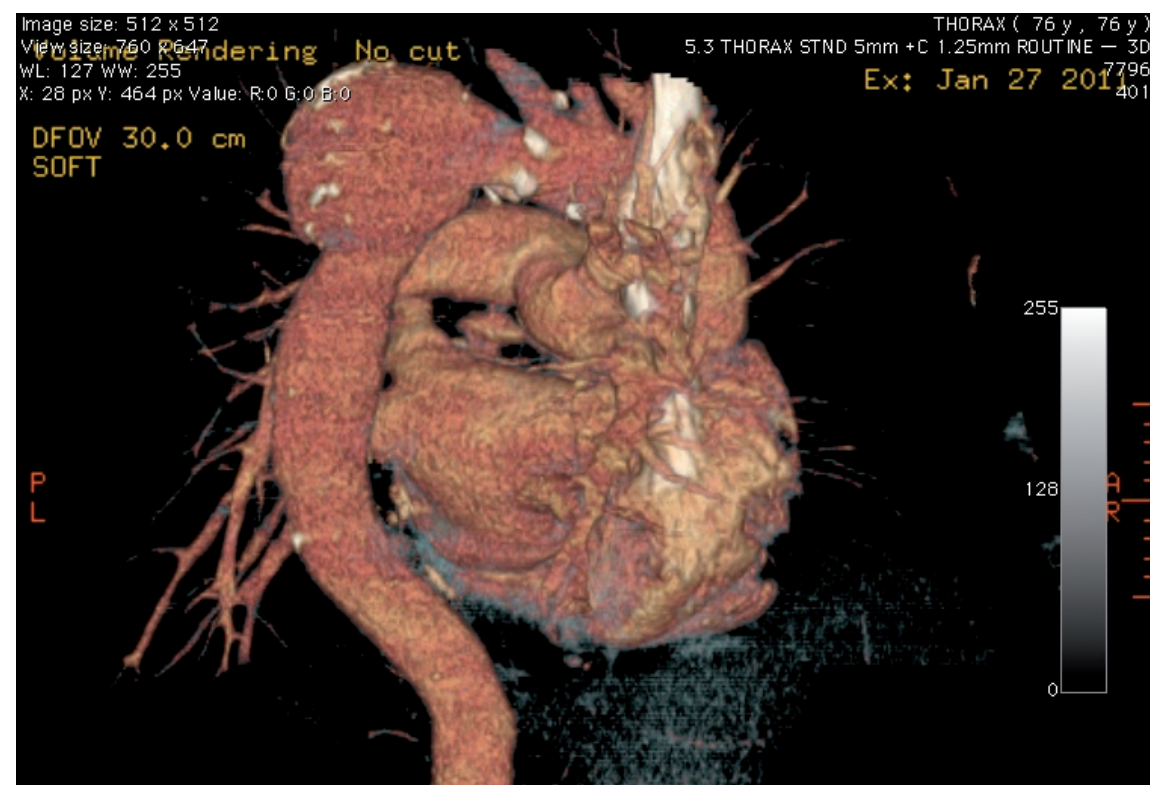

Figure 1. - Preoperative 3D reconstructed chest CT-scan depicting the saccular aneurysm located immediately after the origin of the left subclavian artery. At the distal end of the aneurysm notice the barely visible end-to-end anastomotic line. 
had a history of aortic coarctation for which in 1976, he had undergone a left thoracotomy, resection and an end-to-end anastomosis. The current CT-scan showed intense calcifications in the resected area of the aorta and the saccular aneurysm. Further examination with angiography revealed the existence of a significant stenosis $80 \%$ in the distal part of the LAD, a patent stent in the first marginal branch and a stenosis of $60 \%$ in the initial part of the RCA with normal left ventricular ejection fraction. Carotid ultrasound showed no severe stenoses.

His medical history included a perineal prostatectomy for prostate cancer, removal of vocal cord papillomas and hypothyroidism on drug therapy.

Given the nature of coronary heart disease, we decided not to deal with it at the same time with the aneurysm. After preoperative preparation and under general anesthesia the patient underwent a percutaneous endovascular stenting (Medtronic Valiant ${ }^{\circledR}$ Thoracic) from the left femoral artery to the descending thoracic aorta of $15 \mathrm{~cm} \times 34 \mathrm{~mm}$, without obstructing the left subclavian artery (LSA) (Figure 2).

The postoperative course was uneventful. The patient underwent transesophageal ultrasound one and six months after surgery, which revealed no evidence of any significant pressure gradient $(7 \mathrm{~mm}$ $\mathrm{Hg}$ ), while the contrast enhanced chest CT scan showed the correct placement of the stented graft, thrombosis in the aneurysm and absence of endoleak (Figure 3).

\section{Discussion}

Although relapse after coarctation repair and complications related to surgical procedures are not common, aneurysm formation, stenosis, or occlusion of bypass grafts are reported. Late aneurysm formation has been reported after every type of surgical coarctation repair. The incidence of aneurysm formation is $9 \%$ and is increasing with time [2].

Postsurgical aneurysm formation is observed with subclavian flap angioplasty in $17 \%$, after patch angioplasty in 5-38\%, after interposition graft repair in $6 \%$, and $3 \%$ with end-to-end anastomosis, in the presence of persistent systemic hypertension or after the use of Dacron sutures. Postsurgical aortic aneurysm may present as false, true, or dissecting. The rupture of such aneurysms is thought to be responsible for approximately $7 \%$ of all deaths [3].

Conservative treatment of aneurysms after surgical coarctation repair remains unpredictable and was associated with a $100 \%$ rate of rupture

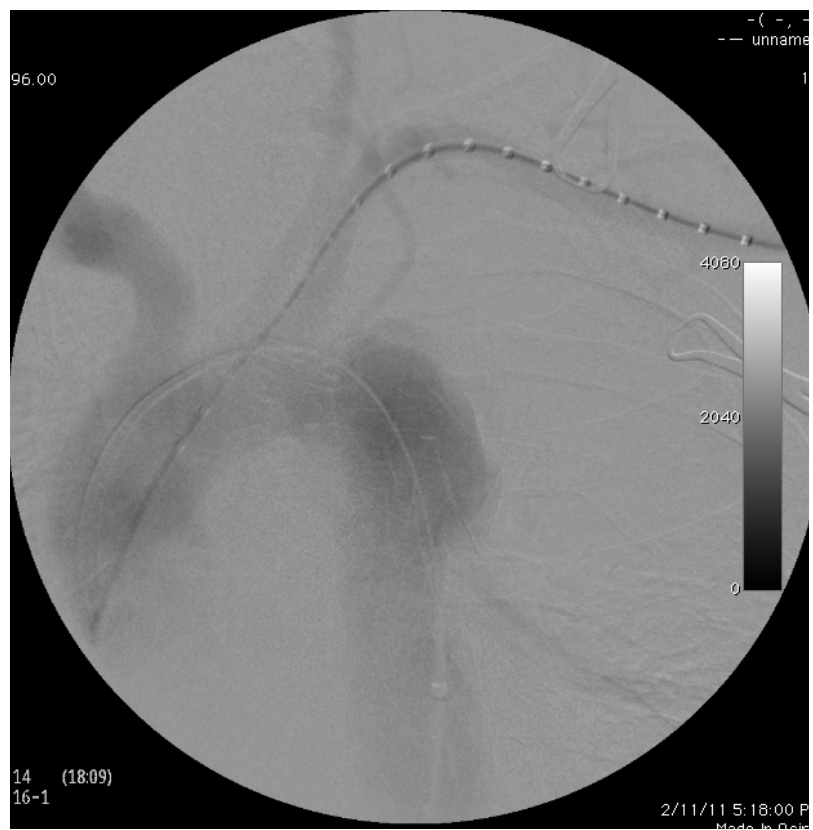

Figure 2. - Intraoperative imaging of the saccular aneurysm and the guide wires inserted from the left subclavian and femoral arteries.

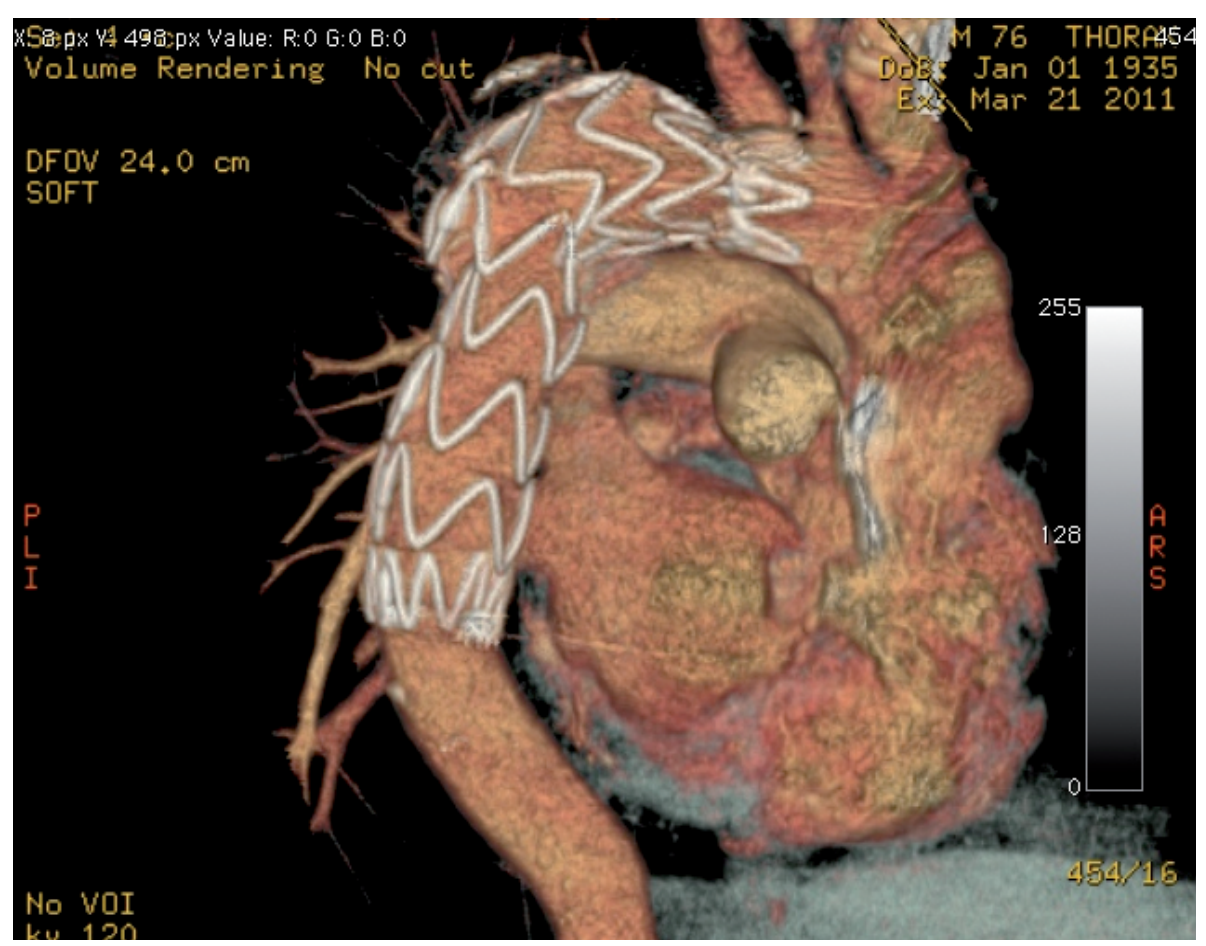

Figure 3. - Postoperative 3D reconstructed chest CT-scan depicting the correct placement of the stented graft without impeding the LSA blood flow.

within 15 years in a single-center experience [4]. Repeat surgery is associated with a $14 \%$ in-hospital mortality rate and morbidity from paraplegia, injury to the central nervous system, or from bleeding [5].

The minimal invasive endovascular stent-graft repair has been shown to be feasible, with acceptable intermediate results with regard to the elective treatment of not only the atherosclerotic aneurysm, but also for anastomotic aneurysms to avoid repeat surgical intervention $[3,6,7]$.

An exhaustive analysis of the literature about elective endovascular therapy of post-coarctation aneurysms showed that the technical success was 
$100 \%$; only one case of death was due to rupture of the aneurysm because of a type 2 endoleak through the left subclavian artery [3]. Although the small series of such endovascular repair, the long-term results of the treatment of both thoracic and abdominal aneurysms revealed infrequent late adverse effects, justifying the use of stent-grafts in younger patients after coarctation surgery [1]. Furthermore, the preservation of the integrity of the aorta protects spinal arteries and avoids neurological events. On the other hand the custom design of each stent-graft currently limits the concept to patients undergoing elective procedures [1].

We adopted a minimal invasive endovascular method, because of the ischemic heart disease and in order to avoid the complications of redo surgery. Imaging techniques were used for accurate planning and executing. Although the existence of calcifications in the anastomotic aortic line and in the saccular aneurysm, using the Medtronic Valiant ${ }^{\circledR}$ Thoracic stent, we had no difficulty to expand it, preserving the left subclavian artery, without endoleak at the end.

In conclusion, endoluminal repair could represent a promising and less-invasive alternative compared with redo operation for elective thoracic aneurysms associated with coarctation repair. In order to test advantage of the endovascu- lar method a prospective randomized trial comparing this method with open surgical repair is mandatory.

\section{References}

1. Ince H, Petzsch M, Rehders T, et al: Percutaneous endovascular repair of aneurysm after previous coarctation surgery. Circulation 2003; 108(24): 2967-70.

2. Botta L, Russo V, Oppido G, et al: Role of endovascular repair in the management of late pseudo-aneurysms following open surgery for aortic coarctation. Eur J Cardiothorac Surg 2009; 36(4): 670-4.

3. Hörmann M, Pavlidis D, Brunkwall J, et al: Long-term results of endovascular repair for thoracic pseudoaneurysms after previous surgical coarctation repair. Interact Cardiovasc Thorac Surg 2011; 13(4): 401-4.

4. Cohen M, Fuster V, Steele PM, et al: Coarctation of the aorta. Long-term follow-up and prediction of outcome after surgical correction. Circulation 1989; 80(4): 840-5.

5. Marcheix B, Lamarche Y, Perrault P, et al: Endovascular management of pseudo-aneurysms after previous surgical repair of congenital aortic coarctation. Eur J Cardiothorac Surg 2007; 31(6): 1004-7.

6. Gawenda M, Aleksic M, Heckenkamp J, et al: Endovascular repair of aneurysm after previous surgical coarctation repair. J Thorac Cardiovasc Surg 2005; 130(4): 1039-43.

7. Zipfel B, Ewert P, Buz S, et al: Endovascular stent-graft repair of late pseudoaneurysms after surgery for aortic coarctation. Ann Thorac Surg. 2011; 91(1): 85-91. 